\title{
Farmland Liquidization and Transaction Costs
}

\author{
Daisuke Takahashi*
}

This paper discusses why progress in farmland liquidization through leasing has been very slow in the agricultural sector in Japan, focusing on the transaction costs related to farmland lease. First, this paper points out that transaction costs are an important constraint for farmland lease, and argues by means of a survey of related studies, why transaction costs have a strong association with farmland. Next, it explores using partial equilibrium analysis to determine how the aggregated demand and supply of farmland is affected by the changes in the farmers' activities that face a transaction cost. Following this, the paper estimates the extent to which farmland lease is affected by the characteristics of the farmland and local communities. The data used in the analysis is the prefectural panel data from the agricultural census for the years 1980, 1990, and 2000; the data excludes Hokkaido, Tokyo, Kanagawa, Osaka, and Okinawa. The result of the econometric analysis shows that the level of farmland lease is related to the variables representing the activities of local communities and the characteristics of farmland such as land improvement and conversion of farmland. These results emphasize the importance of developing and reinforcing institutions and organizations to lower the transaction costs in the farmland market.

Key words: farmland liquidization, transaction cost, partial equilibrium analysis, panel data analysis, local community, Japan.

\section{Introduction}

This paper discusses why progress in farmland liquidization through lease has been very slow in the agricultural sector in Japan, focusing on the transaction costs related to farmland lease. The farmland liquidization in Japan has progressed through leasing, not purchasing, because the land price has risen significantly in anticipation of future conversion for non-agricultural use (Hayami and Godo [13]). Therefore, the reform of the farmland system in order to promote liquidization through leasing, such as the amendment of the Agricultural Land Law and the introduction of the farmland utilization program by the Agricultural Land Utilization Promotion Project, has been an important policy issue. However, the progress of farmland liquidization is still insufficient to adapt to the changing economic conditions of Japanese agriculture.
The farmland system was reformed in 2008 and 2009 in order to promote efficient land use through deregulation. However, there is no consensus why the farmland liquidization has been slow and whether necessary conditions have been satisfied by the reforms. ${ }^{1)}$

Kajii [15] offered a classical study on the economic conditions of farmland lease. Kajii [15] analyzed the production cost in the Kyushu district in 1967 through the Production Cost of Rice, Wheat and Barley and examined the productivity gap between large farms (above $3 \mathrm{ha})$ and small farms (below $30 \mathrm{a}$ ). Kajii [15] finds that the "surplus" (output value-material input cost-wages) of large farms was beyond the "income" (income + wages for family labor) of small farms, which is his proposed economic conditions for farmland lease. Morita [21] confirms that the large farms' surplus has been greater than the small farms' income since the

\footnotetext{
* The University of Tokyo

This refereed paper is based on Journal of Rural Economics, Vol. 82 No.3 (Takahashi [27]), which was awarded the 2011 Journal Article Prize of the Agricultural Economics Society of Japan.

This study was supported by a Grant-in-Aid for JSPS Fellows (20-6536 and 22-260).
} 
1990s in eight agricultural regions except for Hokkaido and concluded that the economic conditions of farmland lease has been continuously satisfied. ${ }^{2)}$

Forty years have passed since the period analyzed by Kajii [15], and the necessary conditions for the development of large-scale tenant farming have been more or less satisfied now. ${ }^{3)}$ On the other hand, progress in farmland liquidization has been slow. This can be attributed to factors which prohibit the adjustment mechanism of land use. Shogenji [25] points out that we should discuss not only potentials to promote farmland lease but also institutions which make the potential effective. Kusakari [18, 19] argues that the Kajii's hypothesis is valid only when the factor market is competitive. The competitiveness does not hold in the real farmland market because of the transaction cost derived from externality, so the productivity gap formed in rent between large and small farms does not necessarily promote farmland liquidization. This paper is based on the contention by Kusakari $[18,19]$ that transaction costs are important obstacles for farmland liquidization. This paper uses a partial equilibrium model to consider the effect of transaction costs on the equilibrium of the farmland lease market.

This paper is organized as follows. In section 2 , I point out that transaction costs related to farmland prohibit its liquidization, and argue by means of a survey of related studies, why transaction costs have a strong association with farmland. In section 3, I analyze how the partial equilibrium of farmland lease market changes when transaction costs are incorporated into farmers' activities. In section 4, the extent to which farmland lease is affected by the characteristics of the farmland and local communities is estimated by means of econometric analysis based on prefectural panel data. In section 5, the conclusion and remaining problems of this paper are discussed.

\section{Survey of Earlier Studies}

\section{1) Farmland and transaction costs}

This paper discusses transaction costs related to farmland lease as the factors that inhibits the market mechanism of land utilization. As Coase [6] argues, if there is no cost in carrying out market transactions, an efficient allocation of resources is achieved with free market transactions. However, in reality, transaction costs ac- crue in the process of negotiation, measurement and enforcement. In this case, the market mechanisms cannot achieve an efficient allocation and governance by institutions and legislation is required. North [23, p.27] attributes the source of transaction costs to the costliness of information, which consists of the costs of measuring the valuable attributes of what is being exchanged and the costs of protecting rights and policing and enforcing agreements. The larger the heterogeneity of exchanged goods and the asymmetry of information among agents is, the higher the measurement costs are. Enforcement costs include the cost of monitoring the activities of the contracted counterpart, the cost of utilizing institutions for ensuring the enforcement of contracts and the risk premium of whether the counterpart obeys the contract.

These studies shed light on the reasons why transaction costs for farmland are high. The heterogeneity of farmland is high because each plot has different characteristics such as fertility and slope and is distributed in particular locations. Correspondingly, the cost of obtaining information on each plot is high. In addition, the surrounding environment and the management of common facilities as well as the production conditions are important characteristics of farmland. Furthermore, the asymmetry of information on characteristics between landlords and tenants is also important with regard to farmland transactions. For example, the lack of information by the counterpart when transacting farmland may lead to mismanagement of farmland by the tenant and underinvestment problems where the tenant is unwilling to invest in plots, being afraid of eviction threats. Thus, the costs of measurement and enforcement of farmland increase.

Earlier studies referred to the importance of transaction costs related to farmland. Kusakari [19] argues that farmland is associated with transaction costs derived from externality because farmland has a property of capital as well as production factors, and production activities affect the environment. Fujie [9] indicates search costs and mismatch costs incurred in association with information asymmetry. Fujie [9] points out that the information about farmland is difficult to obtain because farmland and its tenant and landlord are heterogeneous and some of the characteristics can be known only after cultivation. Kunimitsu [16] argues that un- 
improved farmland is associated with information asymmetry on its characteristics and psychological obsession. Kunimitsu [16] notes that farmland improvement projects mitigate these effects and promote utilization and concentration of farmland. Skoufias [26] distinguishes the variable and fixed variable costs of farmland transactions and confirms the effect of these transaction costs on farmland lease by an econometric model. The variable costs include the costs of monitoring the contract and the landlords' behavior to retain property rights and privileges over their land. The fixed costs include the costs of obtaining information on the costs and benefits of transactions, or negotiating and communicating the terms of transactions between agents.

If the institutions and legislation on farmland transactions function adequately, they can facilitate transactions by mitigating such transaction costs. As institutions on farmland transactions, there are Agricultural Land Commissions that have the principal responsibility of controlling land rights and the Association of Agricultural Land Holding Rationalization that coordinates land use. As an example of the effect of legislative changes on farmland transactions, the farmland utilization program introduced by the Agricultural Land Utilization Promotion Project in 1975 has promoted farmland lease with legal use-right contracts. However, the current farmland system does not play the necessary role of facilitating transactions. Nakajima [22] argues that use-right contracts have disadvantages against off-the-record contracts because transaction costs of utilizing the legal system on a written form are high and landlords are reluctant to lose flexibility of land use and related rights. Nakajima [22] also notes off-the-record contracts cause an underinvestment problem for the landlord that arises from the opportunistic behavior of the tenant. There are cases where institutional incompleteness and policy distortions have led to an increase of transaction costs. Malfunction of regulations on farmland conversion gives an example. Godo [10] insists that the business practices in Japan place too much emphasis on the rights of borrowers and that the landlord is reluctant to lend farmland because the tenant may claim compensation for rescinding the contract if an opportunity for farmland conversion for non-agricultural use arises. Ando [1] finds an increasing number of cases where non-farm- ers outside rural communities inherit farmland because the land price is increased by the anticipation of future conversion of farmland. The inheritance of farmland by non-farmers impedes effective demand for farmland due to the absentee landlord problem and the scatteration problem. Arimoto and Nakajima [2] review the studies on liquidization and concentration of farmland in Japan. Arimoto and Nakajima [2] point out the farmland law system, compensation for tenants' investment, farmland transaction costs and the high potential for farmland conversion as institutional barriers to farmland liquidization.

When considering factors that influence the level of transaction costs, informal constraints based on codes and conventions are important as well as formal institutions based on legislations and property rights (North [23]). Concerning the governance of farmland transactions, the informal organizations such as rural communities and producers' groups are playing important roles as well as the formal organizations such as public administrations and Agricultural Land Commissions. Hayami [12] points out the role of local communities in developing countries in providing a social safety net, protection and management of common resources and promotion of market transactions by ensuring enforcement of contracts. In modern Japanese agriculture, asymmetric information and incompleteness of contracts exists, so local communities based on rural communities are still important for management of common resources and enforcement of contracts.

\section{2) Transaction costs and the farmland market}

While many studies refer to transaction costs of farmland, it needs to be clarified further how transaction costs change the behavior of farmers and the market equilibrium of farmland. Kusakari [18] proposes an agency model in which the farmland lease market is comprised of a landlord and a tenant and the landlord faces transaction costs. Kusakari [18] concludes that distortions derived from transaction costs in the farmland market bring out the productivity gap formed in rent between the landlord and the tenant. In this case, contrary to the proposition by Kajii [15] that the productivity gap brings out farmland liquidization, the productivity gap is observed because farmland liquidization does not occur. This is an important finding in that it 
finds the inverse causality between productivity gap and farmland liquidization while many studies make an empirical analysis of Kajii's proposition. Based on these findings, Kusakari and $\mathrm{Na}-$ kagawa [20] judge whether transaction costs and uncertain returns work as restrictions on the number of land lease contracts in Japan. Kusakari and Nakagawa [20] estimate the transaction costs and the option value coefficients as an index of uncertain returns by applying real option theory and prove the overestimation of the number of the contracts. Fujie [9] considers the effects of transaction costs by proposing a circular model of the farmland lease market which incorporates search costs for farming and mismatch costs after transactions. Skoufias [26] argues that fixed transaction costs make farmers exit the land market and variable transaction costs make the amount of farmland transacted by farmers participating in the farmland market smaller. Ciaian and Swinnen [5] analyze the welfare effect of transaction costs on tenants and landlords by showing the changes of equilibrium of the farmland market because of transaction costs. Carter and Yao [3], Deininger and Jin [7] and Deininger, Jin and Nagarajan [8] propose a model of land lease when transaction costs are incorporated in the households' decision making and consider the effect of households' ability and transaction costs.

Taking the survey of related studies into account, this paper considers and generalizes the relationship between farmland liquidization and transaction costs using a partial equilibrium analysis of the farmland market, focusing on the finding by Kusakari [18, 19] that transaction costs bring out a productivity gap. The proposed model, based on farmers' decision making developed by Carter and Yao [3], Deininger and Jin [7] and Deininger, Jin and Nagarajan [8], analyzes the effect of transaction costs on the aggregated farmland lease market. The propositions from the analysis clarify the effect of transaction costs on farmland liquidization by considering transaction costs for both landlords and tenants. This paper also analyses the effect of the market wage and output price on farmland liquidization with the same framework, which is discussed by Chino [4] and Ito [14].

\section{A Model of the Farmland Lease Market with Transaction Costs}

In this section, I will discuss a model of the farmland lease market with transaction costs related to farmland lease by extending the model of Carter and Yao [3], Deininger and Jin [7] and Deininger, Jin and Nagarajan [8] to an aggregated market model. ${ }^{4)}$ In order to simplify the exposition, only the transaction costs which accrue proportionally to leasing will be considered. In addition, it is assumed that there are a lot of productive farmers as well as low-productivity farmers in the farmland market and that high-productivity farmers become tenants and low-productivity farmers become landlords if transaction costs do not exist. In order to derive the equilibrium condition of the farmland lease market, the following three assumptions are set. First, it is assumed that there is no entry or exit from outside the region in the farmland lease market. Thinking that farmland lease is done within the neighborhood of the region, this assumption can be considered valid. Second, it is assumed that a high-productivity farm will not become a lender and also a low-productivity farm will not become a borrower even if market equilibrium is changed by the influence of transaction costs. Third, it is assumed that the level of transaction costs for lenders and borrowers is the same in the market. In fact, the transaction costs for farmland are considered to be different among plots and among people who deal with farmland. This assumption is made in order to simplify the model and also to focus on the impact of transaction costs which is common in every rural community.

Based on the formulation of Carter and Yao [3], Deininger and Jin [7] and Deininger, Jin and Nagarajan [8], farmers determine the amount of farmland input by solving the optimization problem as equations (1) and (2).

$$
\begin{gathered}
\max _{l_{l_{0} l_{0}, R^{\mathrm{I}}, R^{\mathrm{O}}} \pi=} p \alpha f\left(l_{\mathrm{a}, A} A\right)+w l_{0}-R^{\mathrm{I}}\left(r+t^{\mathrm{in}}\right) \\
+R^{\mathrm{O}}\left(r-t^{\text {out }}\right) \\
\text { s.t. } \\
l_{\mathrm{a}}+l_{0} \leq \bar{L} \\
R^{\mathrm{O}} \leq \bar{A} \\
A=\bar{A}+R^{\mathrm{I}}-R^{\mathrm{O}} \\
l_{\mathrm{a},} l_{0}, R^{\mathrm{I}}, R^{\mathrm{O}} \geq 0
\end{gathered}
$$

In equations (1) and (2), $\pi$ is the profit of farmers. $\bar{L}$ and $\bar{A}$ are endowments of labor and cultivated land. $l_{\mathrm{a}}$ and $l_{\mathrm{o}}$ represent the amount of labor used in agricultural production and in offfarm work. $A$ represents the amount of land used in agricultural production. $R^{\mathrm{I}}$ and $R^{\mathrm{O}}$ rep- 
resent the net amount of land rented-in and rented-out, respectively. ${ }^{5)} p$ is the output price, $w$ is the wage of off-farm labor, and $r$ is the rent of farmland. $t^{\text {in }}$ represents transaction costs which are additionally paid when borrowing the farmland, whereas $t^{\text {out }}$ represents transaction costs which accrue for a landlord when lending the farmland. $\alpha f\left(l_{\mathrm{a},} A\right)$ characterizes production function, and $\alpha$ represents production technology of the farmer. I assume that the production function satisfies, $f_{l_{a}}>0, f_{A}>0, f_{l_{l}, l_{a}}<0, f_{A, A}<0$, $f_{l_{2, A}}>0, f_{l_{a,}, l_{A}, A}-f_{l_{2, A}}^{2}>0$.

The first-order conditions of optimization in this case are equations (3)-(5). ${ }^{6)}$

$$
\begin{gathered}
p \alpha f_{l_{\mathrm{a}}}\left(l_{\mathrm{a},}, A\right)=w \\
\frac{\partial \pi}{\partial R^{\mathrm{I}}}=p \alpha f_{A}\left(l_{\mathrm{a}, A} A\right)-\left(r+t^{\text {in }}\right) \leq 0 ; R^{\mathrm{I}} \frac{\partial \pi}{\partial R^{\mathrm{I}}}=0 \\
\frac{\partial \pi}{\partial R^{\mathrm{O}}}=-p \alpha f_{A}\left(l_{\mathrm{a},} A\right)+\left(r-t^{\text {out }}\right) \leq 0 ; R^{\mathrm{O}} \frac{\partial \pi}{\partial R^{\mathrm{O}}}=0
\end{gathered}
$$

If $R^{\mathrm{I}}>0$ and $R^{\mathrm{O}}=0$, equation (4) holds with equality and equation (5) holds with strict inequality, so the farmer will lease in farmland. If $R^{\mathrm{I}}=0$ and $R^{\mathrm{O}}>0$, equation (4) holds with strict inequality and equation (5) holds with equality, so the farmer will lease out farmland. The condition $R^{\mathrm{I}}>0$ and $R^{0}>0$ is not possible by definition. If $R^{\mathrm{I}}=0$ and $R^{\mathrm{O}}=0$, the farmer will not participate in the farmland lease market. In this case, equations (4) and (5) indicate $r$ $t^{\text {out }} \leq p \alpha f_{A}\left(l_{\mathrm{a},}, A\right) \leq r+t^{\text {in. }}$. In sum, the following conditions are derived.

When leasing in farmland $\left(R^{\mathrm{I}}>0\right.$ and $\left.R^{\mathrm{O}}=0\right)$,

$$
p \alpha f_{A}\left(l_{\mathrm{a},}, A\right)=r+t^{\text {in }}
$$

When leasing out farmland $\left(R^{0}>0\right.$ and $\left.R^{\mathrm{I}}=0\right)$,

$$
p \alpha f_{A}\left(l_{\mathrm{a},}, A\right)=r-t^{\text {out }}
$$

When not participating in leasing $\left(R^{\mathrm{I}}=0\right.$ and $R^{\mathrm{O}}=0$ )

$$
r-t^{\text {out }} \leq p \alpha f_{A}\left(l_{\mathrm{a},}, A\right) \leq r+t^{\text {in }}
$$

The optimal amount of agricultural labor input is determined by equation (3). The optimal labor input when farmer i cultivates the endowed farmland $\bar{A}^{\mathrm{i}}$ is denoted as $\bar{l}_{\mathrm{a}}^{\mathrm{i}}$. Whether farmers participate in farmland leasing or not depends on the level of production technology $\alpha$. If productivity $\alpha$ is so high that equation (6) holds and equation (8) does not hold, the farmer will lease in farmland. If productivity is so low that equation (7) holds and equation (8) does not hold, the farmer will lease out farmland. The two cut-off points whether farmers will participate in the farmland market or not, $\alpha_{u}^{\mathrm{i}}$ and $\alpha_{l}^{\mathrm{i}}$, are derived from equation (8); $\quad \alpha_{u}^{\mathrm{i}}=\frac{r+t^{\mathrm{in}}}{p f_{A}\left(\bar{l}_{\mathrm{a}}^{\mathrm{i}}, \bar{A}^{\mathrm{i}}\right)}$ represents the minimum level of production technology of leasing-in for farmer $\mathrm{i}$, and $\alpha_{l}^{\mathrm{i}}=$ $\frac{r-t^{\text {out }}}{p f_{A}\left(\bar{l}_{\mathrm{a}}^{\mathrm{i}} \bar{A}^{\mathrm{i}}\right)}$ represents the maximum level of production technology of leasing-out for farmer $i$. Therefore, the conditions that farmer i under transaction costs will participate in farmland leasing or not can be summarized as the following equations (9)-(11).

When leasing in farmland

$$
\alpha^{\mathrm{i}}>\frac{r+t^{\mathrm{in}}}{p f_{A}\left(\bar{l}_{\mathrm{a}}^{\mathrm{i}} \bar{A}^{\mathrm{i}}\right)}\left(=\alpha_{u}^{\mathrm{i}}\right)
$$

When leasing out farmland

$$
\alpha^{\mathrm{i}}<\frac{r-t^{\text {out }}}{p f_{A}\left(\bar{l}_{\mathrm{a}}^{\mathrm{i}}, \bar{A}^{\mathrm{i}}\right)}\left(=\alpha_{l}^{\mathrm{i}}\right)
$$

When not participating in leasing

$$
\alpha_{l}^{\mathrm{i}} \leq \alpha^{\mathrm{i}} \leq \alpha_{u}^{\mathrm{i}}
$$

If there are no transaction costs $\left(t^{\text {in }}=t^{\text {out }}=0\right)$, the farmer will utilize the farmland until the marginal productivity of the farmland is equal to the rent. Therefore, unless the marginal productivity of endowed farmland happens to equal the market rent, the farmer will always participate in leasing. In contrast, with transaction costs, a farmer corresponding to equation (11) moves out of the farmland market and cultivates only the self-owned farmland. It is shown from the first-order conditions of farmland and labor inputs that $\frac{\partial \alpha_{u}^{\mathrm{i}}}{\partial t^{\text {in }}}>0$ and $\frac{\partial \alpha_{l}^{\mathrm{i}}}{\partial t^{\text {out }}}<0 .{ }^{7)}$ Therefore, the higher the transaction costs $t^{\text {in }}$ and $t^{\text {out }}$ for tenants and landlords are, the more the farmers exit the land leasing market. In addition, even if a farmer participates in farmland lease, a borrower faces the rent plus transaction $\operatorname{cost} t^{\text {in }}$, and a lender faces the rent minus transaction cost $t^{\text {out; }}$ so the amount of transacted land also decreases.

Here, with transaction costs, the supply function $S$ and the demand function $D$ of the land lease market are defined as follows. In equations (12) and (13), O and I represent a set of lentout farmer and lent-in farmer respectively; namely, $\mathrm{O}=\left\{\alpha^{\mathrm{i}} \mid \alpha^{\mathrm{i}} \leq \alpha_{l}^{\mathrm{i}}\right\}, \mathrm{I}=\left\{\alpha^{\mathrm{j}} \mid \alpha^{\mathrm{j}} \geq \alpha_{u}^{\mathrm{j}}\right\}$. 


$$
\begin{aligned}
& S\left(r-t^{\text {out }}\right)=\sum_{\mathrm{i} \in \mathrm{O}}=s^{\mathrm{i}}\left(r-t^{\text {out }}\right)=\sum_{\mathrm{i} \in \mathrm{O}} \bar{A}^{\mathrm{i}}-\sum_{\mathrm{i} \in \mathrm{O}} A^{\mathrm{i}} \\
& D\left(r+t^{\mathrm{in}}\right)=\sum_{\mathrm{j} \in \mathrm{I}}=d^{\mathrm{j}}\left(r+t^{\mathrm{in}}\right)=\sum_{\mathrm{j} \in \mathrm{I}} A^{\mathrm{j}}-\sum_{\mathrm{j} \in \mathrm{I}} \bar{A}^{\mathrm{j}}
\end{aligned}
$$

The supply function $S$ and the demand function $D$ of the farmland lease market are respectively the functions of $r-t^{\text {out }}$ and $r+t^{\text {in }}$ because the lender and the borrower face market rent with transaction costs. Because demand for farmland $A^{\mathrm{i}}$ and $A^{\mathrm{j}}$ is a decreasing function of market rent, $\frac{\partial S}{\partial r}>0$ and $\frac{\partial D}{\partial r}<0$ are satisfied. Moreover, the supply function $S$ and the demand function $D$ of the farmland lease market are shifted by the changes in $t^{\text {out }}$ and $t^{\text {in }}$ because the number of farmers participating in the market changes; the higher the farmland's transaction costs are, the more the farmers move out of the farmland lease market. The effect of transaction costs on farmland demand and supply by forcing farmers out is denoted as $\frac{\partial D}{\partial t^{\text {in }}}$ and $\frac{\partial S}{\partial t^{\text {out }}}$, and the conditions $\frac{\partial S}{\partial t^{\text {out }}}<0$ and $\frac{\partial D}{\partial t^{\text {in }}}<0$ hold.

The equilibrium condition of the farmland lease market is that demand and supply of farmland is equal; in other words, the following equation (14) is satisfied.

$$
S\left(r-t^{\text {out }}\right)=D\left(r+t^{\text {in }}\right)
$$

Hereafter, $r^{\mathrm{t}}$ represents the market equilibrium rent when transaction cost exists, and $Q^{\mathrm{t}}$ represents the area of farmland leased. In addition, $r^{*}$ is the market equilibrium rent and $Q^{*}$ is the area of farmland leased when there is no transaction cost. By comparing $Q^{\mathrm{t}}$ with $Q^{*}$ and $r^{t}$ with $r^{*}$, the impact of transaction costs on the farmland lease market is analyzed.

The equilibrium condition for the farmland lease market with transaction costs is shown in a graph as Figure 1. First, because of the effect of transaction costs, the farmers corresponding to equation (11) will exit the farmland market. Thus, the demand and supply curve shifts when there are transaction costs. Moreover, the farmers participating in leasing will face rent with transaction costs. Thus, the demand and supply curve shifts as the demand and supply curve becomes the functions of $r+t^{\text {in }}$ and $r-t^{\text {out }}$, respectively. These two shifts are simultaneously caused by the effects of transaction costs. Thus, the equilibrium moves from $E_{0}$ to $E$, the farmland area leased decreases from $Q^{*}$ when there are no transaction costs to $Q^{\mathrm{t}}$, and market equilibrium rent changes from $r^{*}$ to $r^{\mathrm{t}}$.

The changes in transacted farmland area and market equilibrium rent with transaction costs can be calculated by a linear approximation of demand and supply functions, equations (15) and (16). The derivation of equations (15) and (16) is shown in the appendix. ${ }^{8)}$

$$
\begin{aligned}
Q^{\mathrm{t} \approx Q^{*}}+\left(\frac{S^{\prime}\left(r^{*}\right) D^{\prime}\left(r^{*}\right)}{S^{\prime}\left(r^{*}\right)-D^{\prime}\left(r^{*}\right)}\right) t^{\text {in }}+\left(\frac{S^{\prime}\left(r^{*}\right)\left(\frac{\partial D\left(r^{*}\right)}{\partial t^{\text {in }}}\right)}{S^{\prime}\left(r^{*}\right)-D^{\prime}\left(r^{*}\right)}\right) t^{\text {in }} \\
+\left(\frac{S^{\prime}\left(r^{*}\right) D^{\prime}\left(r^{*}\right)}{S^{\prime}\left(r^{*}\right)-D^{\prime}\left(r^{*}\right)}\right) t^{\text {out }}-\left(\frac{D^{\prime}\left(r^{*}\right)\left(\frac{\partial S\left(r^{*}\right)}{\partial t^{\text {out }}}\right)}{S^{\prime}\left(r^{*}\right)-D^{\prime}\left(r^{*}\right)}\right) t^{\text {out }}(15) \\
r^{\mathrm{t} \approx r^{*}}+\left(\frac{D^{\prime}\left(r^{*}\right)}{S^{\prime}\left(r^{*}\right)-D^{\prime}\left(r^{*}\right)}\right) t^{\text {in }}+\left(\frac{\frac{\partial D\left(r^{*}\right)}{\partial t^{\text {in }}}}{S^{\prime}\left(r^{*}\right)-D^{\prime}\left(r^{*}\right)}\right) t^{\text {in }} \\
+\left(\frac{S^{\prime}\left(r^{*}\right)}{S^{\prime}\left(r^{*}\right)-D^{\prime}\left(r^{*}\right)}\right) t^{\text {out }}-\left(\frac{\frac{\partial S\left(r^{*}\right)}{\partial t^{\text {out }}}}{S^{\prime}\left(r^{*}\right)-D^{\prime}\left(r^{*}\right)}\right) t^{\text {out }}(16)
\end{aligned}
$$

In the right-hand side of equations (15) and (16), the second and third terms represent the effect of transaction costs $t^{\text {in }}$ for a borrower on the area of leased farmland and market equilibrium rent, and the fourth and fifth terms represent the impact transaction costs $t^{\text {out }}$ for a lender. The second and fourth terms represent the effect of forcing farmers out of the market due to transaction costs, and the third and fifth terms represent the effect of changing the market rent by transaction costs on the transacted farmland and market equilibrium rent. Because $S^{\prime}(r)>0, D^{\prime}(r)<0, \frac{\partial S\left(r^{*}\right)}{\partial t^{\text {out }}}<0$, and $\frac{\partial D\left(r^{*}\right)}{\partial t^{\text {in }}}<0$, the second to fifth terms in the right-hand side of equation (15) are negative, which confirms that transaction costs impede farmland leasing. Moreover, that the second and third terms in the right-hand side of equation (16) are negative and the fourth and fifth terms are positive means that transaction costs for the landlord raise the market rent and transaction costs for the tenant bring down the market rent.

These results can be summarized as the following propositions. 


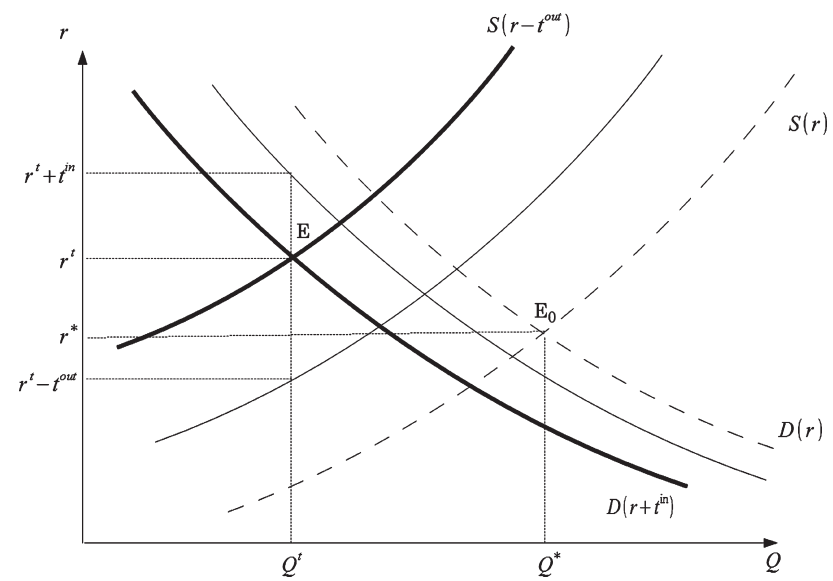

Figure 1. The partial equilibrium of farmland lease market under the transaction costs

Proposition 1. Because of transaction costs, the tenant faces rent higher than the market equilibrium rent and the landlord faces rent lower than the market equilibrium rent. Transaction costs hinder farmland liquidization by forcing some farmers out of the farmland lease market and decreasing the leased farmland area of farmers who participate in farmland lease.

Proposition 2. Because of transaction costs, market equilibrium rent changes. The higher the transaction costs for the tenant are, the more the market rent increases and also the higher the transaction costs for the landlord are, the more the market rent declines.

Thus, with transaction costs, a farmer makes decisions based on the rent which includes transaction costs, as shown in equations (6)-(8), not based on the observed market rent $r^{t}$. The tenant faces a rent higher than the market rent and the landlord faces a rent lower than the market rent; farmland lease is thus inhibited. Kusakari [18, 19] states that the productivity gap formed in rent between large and small farmers does not necessarily promote farmland liquidization and the causality of Kajii's hypothesis is reversed because in fact the insufficient farmland liquidization causes the scale gap. The farmland market model proposed in this paper generalizes the findings of Kusakari [18, 19]; the model takes it into consideration that transaction costs are imposed on the landlord and the tenant, and that some farmers are forced out of the farmland market by transaction costs.

Note that the effect of the change of exogenous variables of the model affecting supply and demand of farmland, such as off-farm wage $w$ and output price $p$, is the same regardless of the presence of transaction costs. The effect which a change of off-farm wage $w$ makes on the equilibrium of farmland lease market is derived from the first-order conditions for the factor inputs as. $\frac{\partial A}{\partial w}<0 .{ }^{9)}$ Therefore, the increase of market wage $w$ decreases demand for farmland and increases supply. Whether farmland lease is promoted when market wage $w$ rises depends on how much the demand and supply curve shifts as a result of the change in market wage, which cannot be determined uniquely. For instance, if the increase in wage has a significant impact on part-time farmers, the potential farmland lenders, the increase in wage is considered to promote farmland liquidization. Similarly, since $\frac{\partial A}{\partial p}>0$ holds, the decline of output price $p$ decreases farmland demand and increases farmland supply. In addition, since $\frac{\partial A}{\partial \alpha}>0$, if the landlord's technology level $\alpha^{\mathrm{i}}$ is low and the tenant's technology level $\alpha^{\mathrm{j}}$ is high, farmland liquidization is promoted. These findings are summarized as the following proposition 3 .

Proposition 3. The increase of market wage $w$ and the decline of output price $p$ decrease demand and increase supply of farmland. Thus, whether farmland liquidization proceeds depends on the degree of the farmland demand and supply curve's shift caused by exogenous variables, not being determined uniquely. Moreover, the lower the lender's technology level $\alpha^{\mathrm{i}}$ 
is and the higher the borrower's technology level is, in other words, the bigger the technological gap between the tenant and the landlord is, the more the farmland liquidization proceeds.

Since Proposition 3 holds regardless of the existence of transaction costs, it implies the findings of previous research about the validity of the effect even if transaction costs exist. For example, Chino [4] analyzed the three factors causing structural changes in agriculture, namely (1) ratio of rice price to off-farm wage, (2) rate of acreage control areas in total paddy field and (3) unit-cost ratio, representing economies of scale. According to Chino [4], decline in the rice price causes structural changes for scale enlargement through the exit of inefficient and high-cost managements. The result of econometric analysis by Chino [4] shows the decline of rice price is associated with relative scale enlargement (increase of share of farmers with more than 2.0 ha in total sales volume), but it is ambiguous whether the decline of rice price is associated with absolute scale enlargement (increase of share of farmers with more than 2.0 ha in number of farmers). Ito [14] states that the decline of the price of rice causes structural adjustment through the exit of small-size farmers if the farmland market functions, but leads to abandonment of farmland if not. The farmland lease model shown in this paper recognizes the importance of this previous research's implications. At the same time, this paper considers the effect of transaction costs, which is not clearly assumed in the econometric analysis in the previous research.

\section{Econometric Analysis}

\section{1) Sample and period of the analysis}

In this section, the empirical analysis is shown in order to discuss the factors affecting transaction costs, based on the three propositions in the previous section about effects of transaction costs on farmland lease.

There are two approaches for investigating the effects of transaction costs on farmland liquidization; an approach for analyzing the activities of each household, shown in equations (6)(8), and an approach for analyzing the equilibrium of the market under the effects of transaction costs. However, in order to analyze the activities of each household, it is necessary to collect information on not only characteristics of farmers but also characteristics of farmland, communities and other farmers who are potentially able to transact farmland. In addition, it is necessary to collect information on farmers in various regions and with heterogeneity in order to obtain enough variance to make an econometric analysis. Currently, such information is not available to the author. On the other hand, various and reliable data are available with aggregated prefectural data from public statistics, such as the Census of Agriculture, the Statistics on Cultivated Land and Planted Area, the Transfer and Change of Agricultural Land and the Survey on Farmland Utilization and Infrastructure Improvement. In this section, I will examine the Propositions 1 and 3 in the previous section with aggregated prefectural data. Proposition 1 states that transaction costs have the effect of forcing part of the farmers out of the market and the effect of reducing the transacted area. However, the aggregated data shows the amount that is actually transacted, so it is impossible to distinguish these two effects. Therefore, I focus on the effect of transaction costs on the amount of transacted farmland. I will not examine Proposition 2, because the focus of this paper is on the effect of transaction costs on farmland liquidization. ${ }^{10)}$

This paper studies the data for 42 prefectures; Hokkaido and Okinawa are excluded because the geographical conditions are different, and Tokyo, Kanagawa and Osaka because the effects of urbanization are strong. The lease of paddy land is analyzed because "upland field" in the public statistics includes various kinds of land such as orchard and pasture. I analyze the years 1980, 1990, and 2000, in which the Census of Agriculture is published. The number of the rural communities surveyed in the census is almost constant.

By simplifying equation (15) and replacing the approximation with an equality, the linear relationship (17) among the transacted farmland $Q_{t, k}$ in community $\mathrm{k}$ in time t, the exogenous variables $\boldsymbol{Z}_{\mathrm{t}, \mathrm{k}}$ which affect the transacted farmland $Q_{\mathrm{t}, \mathrm{k}}^{*}$, and the variables representing the level of transaction costs $T_{\mathrm{t}, \mathrm{k}}$.

$$
Q_{\mathrm{t}, \mathrm{k}}=\boldsymbol{\beta} \cdot Z_{\mathrm{t}, \mathrm{k}}+\boldsymbol{\gamma} \cdot \boldsymbol{T}_{\mathrm{t}, \mathrm{k}}
$$

By summing up equation (17) with respect to each community and dividing by the sum of the amount of farmland in each community $A_{\mathrm{k}}$, a reduced equation that can be analyzed with prefectural data is obtained. I also include the vari- 
ables which are measured at the prefectural level, assuming that the characteristics of farmland are uniform in each prefecture. Furthermore, the average values in each community and the ratios of communities with relevant characteristics are included as explanatory variables, assuming that the amount of farmland in communities and the level of characteristics are uniform. We should note, however, that violation of these assumptions may yield measurement errors. ${ }^{11)} \mathrm{I}$ also include a constant term $c$, an error term $\epsilon_{\mathrm{t}, \mathrm{K}}$, and an individual term $\delta_{\mathrm{K}}$, and make a regression analysis with the following equation (18).

$$
q_{\mathrm{t}, \mathrm{K}}=\boldsymbol{c}+\boldsymbol{\beta} \cdot \boldsymbol{z}_{\mathrm{t}, \mathrm{K}}+\boldsymbol{\gamma} \cdot \boldsymbol{t}_{\mathrm{t}, \mathrm{K}}+\delta_{\mathrm{K}}+\epsilon_{\mathrm{t}, \mathrm{K}}
$$

In equation (18), $q_{\mathrm{t}, \mathrm{K}}$ represents the rate of farmland that is under tenancy in the prefecture $\mathrm{K}$, called the tenancy rate and $\boldsymbol{z}_{\mathrm{t}, \mathrm{K}}$ and $\boldsymbol{t}_{\mathrm{t}, \mathrm{K}}$ represent the variables measured at the level of prefecture $\mathrm{K}$, corresponding to $Z_{\mathrm{t}, \mathrm{k}}$ and $\boldsymbol{T}_{\mathrm{t}, \mathrm{k}}$.

With regard to the explanatory variables related to transaction costs of farmland, such variables are introduced as characteristics of farmland, size of the farmland market in communities and functions of rural communities, referring to the discussion of the previous census analysis such as Shogenji [24]. This is because the theoretical discussion on transaction costs by Coase [6] and North [23] implies that measurement costs about valuable attributes of farmland and enforcement costs on farmland contracts yield transaction costs for farmland and prohibit liquidization. The discussion by $\mathrm{Ku}-$ sakari [18, 19] and Fujie [9] on transaction costs of farmland also implies that transaction costs arise from externality of agricultural production and both formal and informal institutions and legislation related to farmland transactions affect the level of transaction costs. In addition to these variables, I include the exogenous variable related to agricultural production, $\boldsymbol{z}_{\mathrm{t}, \mathrm{K}}$, referring to the previous studies such as Chino [4]. The individual independent variables and their effects on transaction costs and contracts of farmland are discussed below. ${ }^{12)}$

(1) With regard to the characteristics of farmland, "rate of farmland in Agricultural Promotion Area," "rate of improved farmland" and "rate of converted area in total paddy field" are introduced. The higher the rate of farmland in an Agricultural Promotion Area, the more actively farmland is transacted; farmland in an
Agricultural Promotion Area can be leased through the farmland utilization program, which incurs lower transaction costs than a lease based on the Agricultural Land Law, and is less likely to be converted for nonagricultural use because of regulations on farmland conversion. The higher the rate of improved farmland, the more actively farmland is transacted because farmland becomes more productive and has lower uncertainty as to its quality (Kunimitsu [16]). The higher the rate of converted area in total paddy field is, the more the farmland liquidization is restricted because the tendency for the landlords to reserve farmland with expectation of future conversion leads to higher transaction costs (Godo [10]).

(2) With regard to the size of the farmland market in local communities, "area of paddy field in local communities" and "rate of farmers in local communities" are introduced, which represent the size of the farmland lease market in local communities. Fujie [9] explains that the rate of abandoned land is low if the search costs related to characteristics of farmland and its borrowers and lenders is. The smaller the area of paddy field in local communities is, and the lower the rate of farmers is, the smaller the market size of farmland in local communities with less information asymmetry. On the other hand, if the market size of farmland in local communities is small, the mismatch cost after transactions becomes higher. In addition, if the rate of farmers declines, it becomes more difficult to maintain the functions of rural communities. Therefore, it is impossible to decide the effects of these variables on farmland liquidization a priori.

(3) With regard to the functions of local communities, "rate of the local communities within 30 minutes to DID (densely inhabited district)," "rate of the local communities with more than 3 meetings" and "rate of local communities with producers' group" are introduced. These variables represent the effects of informal constraints on transaction costs, which are pointed out by North [23]. As Kusakari [19] argues, if traditional institutions affect farmland liquidization, it means that implicit local rules based on traditions and conventions contribute to the coordination of farmland use, implying the existence of transaction costs of farmland. The required commuting time to a DID represents the level of access to densely inhabited districts and daily 
living facilities. If less time is required for arriving at a DID, the living conditions for maintaining functions of local communities are arranged better, and the role of local communities in lowering transaction costs are performed more actively. It should be noted that the required commuting time to a DID may represent not only the level of functions of local communities but also the relationship between communities and labor markets. The more meetings local communities have, the more actively the information is exchanged within the communities, and the transaction costs of acquiring information on farmland is reduced. Furthermore, if producers' groups exist in local communities, information exchange and coordination of farmland is made in the process of organizing production behaviors.

(4) With regard to production conditions, "rate of acreage control areas in total paddy field," "ratio of rice price to average off-farm wage" and "unit cost ratio" are introduced. As discussed in Proposition 3, these exogenous variables on production conditions will affect farmland liquidization if transaction costs exist. These variables on production conditions are the same as the ones in Chino [4]. The rate of acreage control areas in total paddy field is introduced in order to consider the effect of the acreage control policy. Kusakari [17] shows a uniform acreage control in the analysis period prohibits farmland liquidization by forcing on the large-size farmers, potential borrowers of land, a greater loss of income. The ratio of rice price to average off-farm wage is also included in the explanatory variables. Considering the discussion of Chino [4] and Ito [14] as well as the implications of Proposition 3, the lower the rice price is, and the higher the off-farm wage is, the more farmland liquidization is promoted because of the exit of small-size farmers. Furthermore, Proposition 3 indicates that the productivity gap between large and small farmers promotes farmland liquidization. The unit cost ratio, the ratio of production cost per area between large and small farmers, represents the economies of scale, as argued by Chino [4].

The individual effect $\delta_{\mathrm{K}}$ represents time-invariant geographical and psychological factors. The effect of regional variety of rural communities on farmland lease is included in the individual effect because regional classification of rural communities does not vary. The psychological effect related to farmland, such as attachment to land, is also included in the individual effect. The speed of farmland liquidization has apparently regional characteristics, as shown in Figure 2 , because rural communities are located in diversified regional areas. Inclusion of the individual effect through panel data analysis can control the omitted variables bias on the estimated coefficients of other variables.

The dependent variable of this analysis is the tenancy rate, which is the ratio of the amount of leased-in paddy field to the amount of total paddy field. Two kinds of data source are used to measure the amount of leased-in paddy field. One is the Census of Agriculture, and the other is the Transfer and Change of Agricultural Land. The Census of Agriculture shows the amount of transacted leased-in at the time when the survey was conducted. The leased-in farmland in the Census includes not only the farmland under formal contracts based on the Agricultural Land Law and the Agricultural Management Reinforcement Law but also farmland under off-the-record farming contracts and farmland where most of the cultivation process is outsourced to other farmers. The amount of leased-in farmland in the Census, however, shows the status of tenanted farmland when the survey was conducted, not the amount which was actually transacted in the surveyed time. The period of tenanted farmland has lagged behind the period of the survey when the explanatory variables are measured. This lag may weaken the power of explanatory variables. Therefore, I also obtained the amount of leasedin paddy field from the Transfer and Change of Agricultural Land. The Transfer and Change of Agricultural Land only reports the amount of formally contracted farmland in every year. It deserves reservations to measure the amount of tenanted farmland with the Transfer and Change of Agricultural Land because farmers may choose an off-the-record farming contract when transaction costs exist, as argued by $\mathrm{Na}-$ kajima [22].

The averages and standard deviations, as well as the sign conditions implied by the above discussion are shown in Table 1 . The variables which are not proportions, "area of paddy field in local communities" and "ratio of rice price to average off-farm wage" are measured as log transformations.

Figure 2 shows the extent of farmland liquidi- 
Farmland Liquidization and Transaction Costs

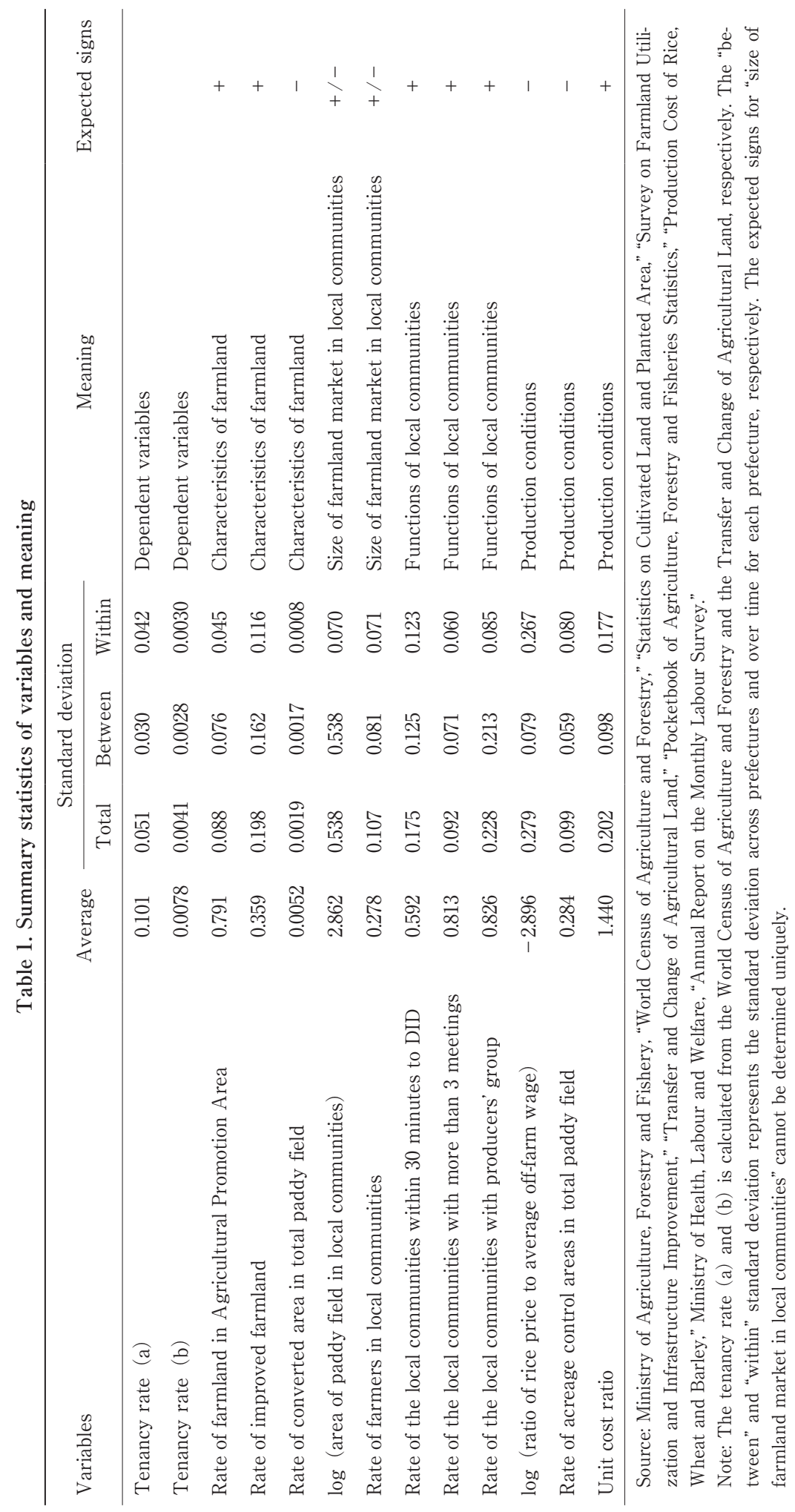




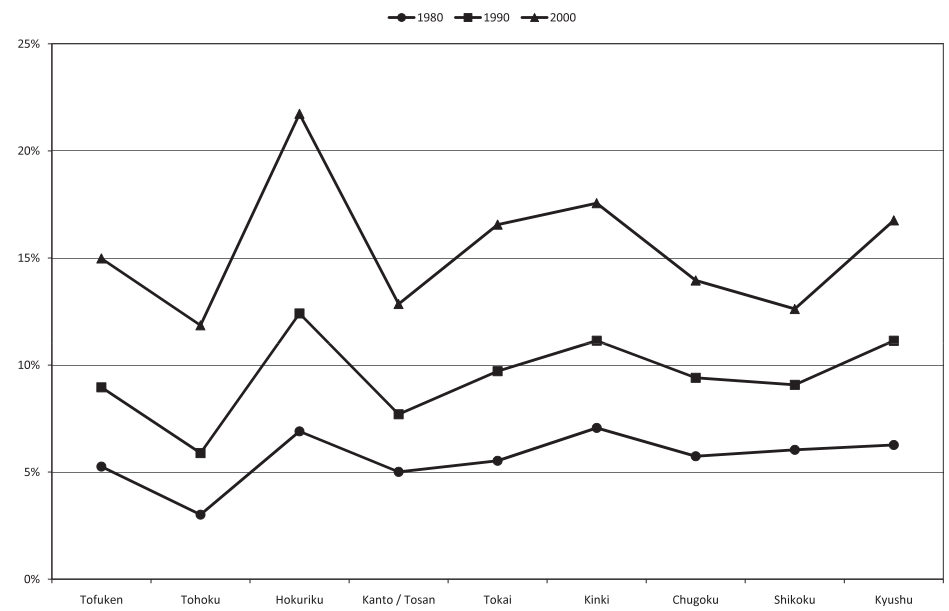

Figure 2. Regional trend of tenancy rate

Source: "World Census of Agriculture and Forestry" and "Statistics on Cultivated Land and Planted Area."

zation within each agricultural region. Farmland liquidization is advancing in the Hokuriku, Kinki and Kyushu regions and falling behind in Tohoku, Kanto-Tosan, and Shikoku. Farmland liquidization has been advancing over time, and the progress is larger between 1990 and 2000 than between 1980 and 1990. The total average of tenancy rate is $5.3 \%$ in 1980, $9.0 \%$ in 1990 and $15.0 \%$ in 2000 . The increase of tenancy rate is mainly brought about by the increased amount of leased-in farmland, not the decreased amount of total land. The total paddy field decreases $13.8 \%$ between 1980 and 2000; the total is 2.80 million ha in 1980, 2.61 million ha in 1990 and 2.42 million ha in 2000. On the other hand, the amount of leased-in paddy field has increased $146 \%$; it is 147 thousand ha in 1980, 234 thousand ha in 1990 and 362 thousand ha in 2000. The variation among regions increases over time as well as the average. The standard deviation among prefectures is 0.19 in 1980, 0.30 in 1990 and 0.45 in 2000. These statistics shows the characteristics that are fixed over time and that vary among regions.

\section{2) Results of econometric analysis}

The results of econometric analysis estimation in equation (18) are shown in Table 2. The constant term is not shown in Table 2 .

The three major methods of panel analysis are used, namely pooling estimation, fixed effect estimation, and random effect estimation. Because the theory does not assume an existence of individual effect or probability distribution of error terms, the most appropriate estimation is chosen from the results of these three estimation methods by a statistical test. ${ }^{13)}$

First, the results of estimation (1)-(3) in Table 2 are discussed, in which the tenancy rate is based on the Census of Agriculture. These results are obtained from pooling estimation, fixed effect estimation and random effect estimation. The result of the Breusch-Pagan test shows that the null hypothesis of no individual effect is significantly rejected $\quad\left(\chi^{2}(1)=32.64, \quad p\right.$-value $<$ 0.001). Therefore the pooling estimation of (1) is not consistent. In addition, the Hausman test does not reject the null hypothesis that individual effect is not correlated to independent variables $\left(\chi^{2}(11)=7.10, \quad p\right.$-value $\left.=0.791\right)$. Therefore, the random effect estimation in (3) is more efficient than the fixed effect estimation in (2). These results of statistical tests show that random effect estimation in (3) is the most efficient method, so I will mainly discuss the result of estimation (3).

From the result in (3), not only the variables about production conditions of paddy field, but also the variables of characteristics of farmland, size of the farmland market in local communities and functions of local communities are significant, and the sign is consistent with expectation. First the estimation regarding the variables about characteristics of farmland is discussed. "Rate of improved farmland" has a significant positive effect on farmland liquidization. According to the estimation, an increase of 
Farmland Liquidization and Transaction Costs

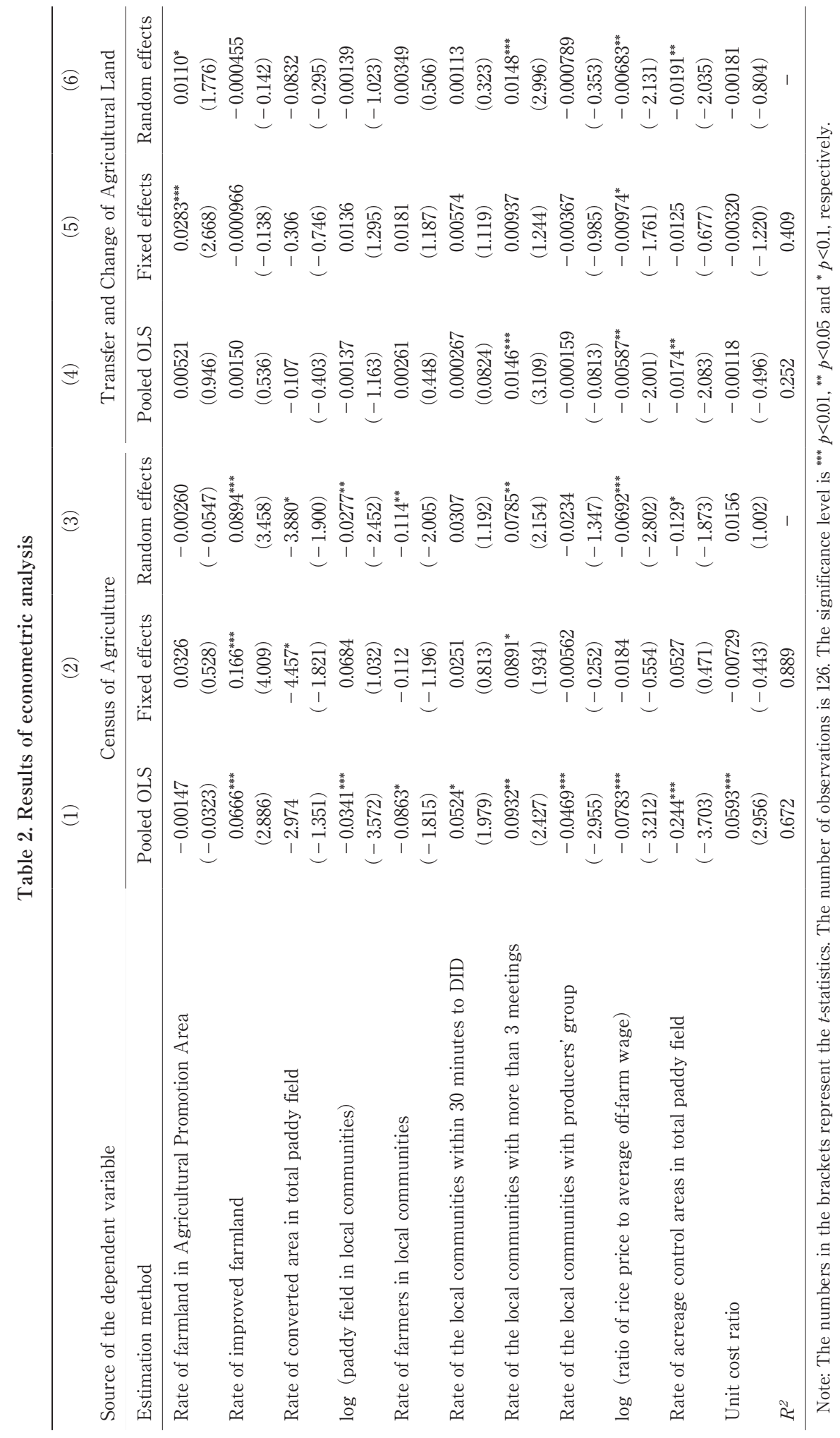


the rate of land improvement by 1 percent will raise the tenancy rate by 0.17 percent. In addition, "rate of converted area in total paddy field" has a significantly negative relationship with tenancy rate. The estimation indicates that an increase of 1 percent of the rate of converted area decreases the rate of farmland lease by 3.9 percent. "Rate of farmland in Agricultural Promotion Area" cannot be confirmed to have a significant effect on tenancy rate. Second, regarding the estimation of the size of the farmland market in local communities, the coefficients of "area of paddy field in local communities" and "rate of farmers in local communities" are significantly negative. Third, looking at the variables related to functions of local communities, "rate of local communities with more than 3 meetings" has a significantly positive effect on the tenancy rate, which shows that activities of local communities promote farmland liquidization. Finally, regarding the variable about production conditions, "ratio of rice price to average off-farm wage" and "rate of acreage control areas in total paddy field" are significant and have the expected signs.

The results of econometric analysis are shown in (4)-(6) in Table 2, in which the independent variables are calculated from the Transfer and Change of Agricultural Land. Estimation (4) is about the result of pooling estimation, (5) is about fixed effect estimation and (6) is about random effect estimation. With the Breusch-Pagan Test, the null hypothesis that the variance of individual effect is 0 is significantly rejected $\left(\chi^{2}(1)=7.74, \quad p\right.$-value $\left.=0.005\right)$; the pooling estimation in (4) is not consistent. In addition, with the Hausman test, the null hypothesis that the individual effect has no correlation with the independent variable cannot be rejected $\left(\chi^{2}(11)=12.91, p\right.$-value $\left.=0.299\right)$. Therefore, the random effect estimation in (6) is more efficient than the fixed effect estimation in (5) so I will mainly discuss the result of the random effect estimation.

The result of estimation (6) generally satisfies the expected sign conditions, although the significance level is lower than the result of estimation (3). First, looking at the variables related to characteristics of farmland, "rate of farmland in Agricultural Promotion Area" has positive correlation with the tenancy rate. The area of leased farmland area obtained from the Transfer and Change of Agricultural Land is based on legal contracts. Therefore, the estimation result (6) may reflect the fact that zoning the farmland promotes farmland liquidization based on formal lease contracts. Second, the variables representing size of the farmland market in local communities do not have a significant effect on the tenancy rate. Third, regarding the variables about functions of local communities, "rate of the local communities with more than 3 meetings" is positive and significant, but the other variables are not significant. Finally, regarding the variables of production conditions, the coefficients of "ratio of rice price to average off-farm wage" and "rate of acreage control areas in total paddy field" are significant with expected signs, although "unit cost ratio" is not significant. In addition, comparing estimation results of (3) and (6), although the signs are generally the same, there are some differences in significance. For example, "rate of farmland in Agricultural Promotion Area" is not significant in (3), but is significant in (6). This is interpreted to mean that although zoning of farmland promotes formal lease contracts, it does not necessarily promote off-the-record farming contracts. Conversely, "rate of improved farmland" representing characteristics of farmland, and "area of paddy field in local communities" as well as "rate of farmers in local communities" representing size of the farmland market in local communities are significant in (3) but not in (6). This can be considered as follows: it is difficult to take opportunistic actions if the transactions are based on formal contracts, so asymmetry of information about characteristics of farmland and the quality of tenants and landlords impedes only off-the-record farming contracts but does not necessarily impede legal farming contracts.

The results of econometric analysis in Table 2, in connection with the discussion of when to set independent variables, can be interpreted as follows. First, the variables about characteristics of farmland have a significant correlation with the tenancy rate, such as "rate of improved farmland" and "rate of converted area in total paddy field" in (3) and "rate of farmland in Agricultural Promotion Area" in (6). This result can be interpreted as evidence that the impact of transaction costs is derived from externality of agricultural production, as discussed by Kusakari [18, 19] and Fujie [9]. Consequently, it is considered that policy interventions such as im- 
plementation of farmland improvement projects, proper zoning of farmland and strengthening of regulations on farmland conversion promote farmland liquidization by decreasing farmland transaction costs. "Area of paddy field in local communities" and "rate of farmers in local communities" in estimation results (3) are significantly and negatively related to the tenancy rate; the smaller the size of the farmland market in local communities is, the less the asymmetry of information will occur. This result also suggests the effect of transaction costs on farmland liquidization. Furthermore, that "rate of local communities with more than 3 meetings" in estimation results (3) and (6) is significant shows that an informal system of local communities decreases the transaction cost for farmland. Hence, a policy such as supporting the function of the local communities can also promote farmland liquidization. These results are consistent with the implication of Proposition 1 stating that farmland liquidization will be inhibited by the effect of transaction costs. Finally, that "ratio of rice price to average off-farm wage" and "rate of converted area in total paddy field" in estimation results (3) and (6) are significant means that even in the case of considering an impact of transaction cost, the implication of previous research about the relationship between production conditions and farmland liquidization is still valid, as discussed in Proposition 3. It should be noted that the significance and magnitude of coefficients obtained by analysis depends on the system. For example, if the inheritance tax and alienated income tax are raised and the value of farmland as asset decreases, the effect in which farmland conversion impedes farmland liquidization may become smaller even when farmland conversion is undertaken constantly.

\section{Conclusions}

This paper discusses the potential effects of transaction costs for impeding farmland liquidization, and analyzes how transaction costs change the amount of tenanted farmland and the market rent by a partial equilibrium model of the farmland market which is based on the households' decision making model developed by Carter and Yao [3] and Deininger and Jin [7]. The results of the model analysis shows that transaction costs related to farmland inhibit liquidization with two simultaneous effects: the effect of changing the rent that farmers face and the effect of forcing part of the farmers out of farmland lease. This paper also makes a regression analysis to explain the level of tenancy rate, calculated from two sources of statistics, the Census of Agriculture and the Transfer and Change of Agricultural Land. The results shows the tenancy rate is significantly associated with the characteristics of farmland, such as "rate of farmland in Agricultural Promotion Area," "rate of improved farmland" and "rate of converted area in total paddy field," and the level of rural community functions, such as "rate of the local communities with more than 3 meetings." These results indicate the factors which are related to transaction costs influencing farmland lease. These findings imply that the deregulation of the land system may not necessarily lead to efficient use of farmland because a variety of socioeconomic factors in addition to production conditions affect farmland liquidization. Rather, the government should develop and reinforce institutions to mitigate transaction costs, such as public investment in infrastructure projects and strengthening regulations on farmland conversions. The subsidy for rural communities' activities also functions as a structural adjustment policy because communities have the externality of mitigating transaction costs. The efficiency of farmland use through market mechanisms is possible only when these governance systems of market transactions are developed adequately.

The findings of this paper need to be discussed further using less aggregated data on households and communities. With the aggregated prefectural data used in this paper, it is impossible to analyze the effect of transaction costs that individual farmers face, such as the level of scatteration and relationship between landlords and tenants. An analysis of the relationship between individual farmers' activities and characteristics of households and communities will make clearer the factors behind transaction costs related to farmland. The effects of local communities' functions on agricultural structure can be examined further by the Rural Community Cards, which combines the survey on management entities and rural communities in the Census of Agriculture. Furthermore the econometric analysis in this paper has the problem of endogeneity bias; the independent variables are determined in the agricultural structure and influenced by the dependent variable. 
These econometric biases can be avoided by an instrumental variables method with adequate instruments. These problems remain as a matter to be discussed in the future studies.

Appendix: Mathematical Derivation of Propositions 1 and 2 in Section 3

By differencing equation (14), the equilibrium condition of farmland lease market, with respect to $t^{\text {in }}$ and $t^{\text {out }}$ the following equations (19) and (20) are obtained.

$$
\begin{gathered}
\frac{\partial S\left(r-t^{\text {out }}\right)}{\partial r} \frac{\partial r}{\partial t^{\text {in }}}=\frac{\partial D\left(r+t^{\text {in }}\right)}{\partial r} \frac{\partial r}{\partial t^{\text {in }}}+\frac{\partial D\left(r+t^{\text {in }}\right)}{\partial r} \\
+\frac{\partial D\left(r+t^{\text {in }}\right)}{\partial t^{\text {in }}} \\
\Leftrightarrow \frac{\partial r}{\partial t^{\text {in }}}=\frac{D^{\prime}\left(r+t^{\text {in }}\right)+\frac{\partial D\left(r+t^{\text {in }}\right)}{\partial t^{\text {in }}}}{S^{\prime}\left(r-t^{\text {out }}\right)-D^{\prime}\left(r+t^{\text {in }}\right)} \\
\frac{\partial S\left(r-t^{\text {out }}\right)}{\partial r} \frac{\partial r}{\partial t^{\text {out }}}-\frac{\partial S\left(r-t^{\text {out }}\right)}{\partial r}+\frac{\partial S\left(r-t^{\text {out }}\right)}{\partial r^{\text {out }}} \\
=\frac{\partial D\left(r+t^{\text {in }}\right)}{\partial r} \frac{\partial r}{\partial t^{\text {out }}} \\
\Leftrightarrow \frac{\partial r}{\partial t^{\text {out }}}=\frac{S^{\prime}\left(r-t^{\text {out }}\right)-\frac{\partial S\left(r-t^{\text {out }}\right)}{\partial t^{\text {out }}}}{S^{\prime}\left(r-t^{\text {out }}\right)-D^{\prime}\left(r+t^{\text {in }}\right)}
\end{gathered}
$$

In equations (19) and (20), $S^{\prime}\left(r-t^{\text {out }}\right)=$ $\frac{\partial S\left(r-t^{\text {out }}\right)}{\partial r}$ and $D^{\prime}\left(r+t^{\text {in }}\right)=\frac{\partial D\left(r+t^{\text {in }}\right)}{\partial r}$. The denominators in the right-hand side of equations (19) and (20) are positive, the numerators in the right-hand side of equations (19) and (20) are negative and positive, respectively, because $S^{\prime}\left(r-t^{\text {out }}\right)>0, D^{\prime}\left(r+t^{\text {in }}\right)<0, \frac{\partial S}{\partial t^{\text {out }}}<0$ and $\frac{\partial D}{\partial t^{\text {in }}}<0$. This means that the transaction cost for borrower $t^{\text {in }}$ decreases the market equilibrium rent and the transaction cost for lender $t^{\text {out }}$ increases the market equilibrium rent.

A linear approximation of market equilibrium rent $r^{t}$ and leased farmland $S\left(r-t^{\text {out }}\right)$ and $D(r$ $\left.+t^{\text {in }}\right)$ in equation (14) at $t^{\text {in }}=0$ and $t^{\text {out }}=0$ gives equations (18) and (19). The derivation of equations (21) and (22) are based on the fact that market equilibrium rent $r^{t}$ is the function of $t^{\text {in }}$ and $t^{\text {out }}$ and that $r^{t}=r^{*}, S\left(r-t^{\text {out }}\right)=D(r+$ $\left.t^{\text {in }}\right)=Q^{*}$ at $t^{\text {in }}=t^{\text {out }}=0$ by definition.

$$
r^{t} \approx r^{*}+\left(\frac{\partial r}{\partial t^{\text {in }}}\right) t^{\text {in }}+\left(\frac{\partial r}{\partial t^{\text {out }}}\right) t^{\text {out }}
$$

$$
\begin{aligned}
& S\left(r-t^{\text {out }}\right) \approx Q^{*}+S^{\prime}\left(r^{*}\right)\left(\frac{\partial r}{\partial t^{\text {in }}}\right) t^{\text {in }} \\
& \quad+S^{\prime}\left(r^{*}\right)\left(\frac{\partial r}{\partial t^{\text {out }}}\right) t^{\text {out }}-S^{\prime}\left(r^{*}\right) t^{\text {out }}+\frac{\partial S\left(r^{*}\right)}{\partial t^{\text {out }}} t^{\text {out }}(22)
\end{aligned}
$$

Finally, substituting the right-hand side of equations (19) and (20) for $\left(\frac{\partial r}{\partial t^{\text {in }}}\right)$ and $\left(\frac{\partial r}{\partial t^{\text {out }}}\right)$ in equations (21) and (22) gives equations (15) and (16).

\section{Data Appendix in Section 4}

Tenancy rate: the amount of leased-in paddy field is from the World Census of Agriculture and Forestry and the Transfer and Change of Agricultural Land. The amount of total paddy field is from the Statistics on Cultivated Land and Planted Area.

Rate of farmland in Agricultural Promotion Area and improved farmland: the amount of farmland in Agricultural Promotion Area and improved farmland is from the Survey on Farmland Utilization and Infrastructure Improvement. The amount of total paddy field is from the Statistics on Cultivated Land and Planted Area.

Paddy field and rate of farmers in local communities: these are from the World Census of Agriculture and Forestry.

Rate of the local communities within 30 minutes of DID, with more than 3 meetings and with producers' group: these are from the World Census of Agriculture and Forestry.

Ratio of rice price to average off-farm wage: the rice price is from the Production Cost of Rice, Wheat and Barley. The average off-farm wage is from the Annual Report on the Monthly Labour Survey.

Rate of acreage control areas in total paddy field: the amount of the acreage control areas is from the Pocketbook of Agriculture, Forestry and Fisheries Statistics. The amount of total paddy field is from the Statistics on Cultivated Land and Planted Area.

Unit cost ratio: the data of production cost to calculate the unit cost ratio is from the Production Cost of Rice, Wheat and Barley.

1) In the Japanese farmland system, farmland leasing is strictly regulated by the Agricultural Land Law. The Agricultural Land Utilization Promotion Project in 1975 deregulated farmland leasing in Agricultural Promotion Areas, which was legislat- 
ed as the Agricultural Land Utilization Law in 1980 and incorporated in the Agricultural Management Reinforcement Law in 1993. The legal framework for farmland leasing had been unchanged during the analysis period of this paper. See Hayami [11] for the farmland system in Japan.

2) See also Hayami [11] with regard to the discussion on the economic conditions for the development of large-scale tenant farming.

3) Kajii [15] analyzed the Farm Household Economy Survey in 1968 and did not find evidence that the surplus of large farms was greater than the income of small farms. Morita [20] also did not confirm the economic condition of leasing in the Shikoku district, partly because of the data limitation of the Production Cost of Rice, Wheat and Barley. In addition, there is room for argument whether the imputed value of family labor in the production cost corresponds to the opportunity cost of farm labor. Therefore, it is open to dispute whether the necessary conditions for the development of large-scale tenant farming have been continuously satisfied nationwide.

4) In the analysis of this paper, farmland liquidization through purchase is not considered. This is because it is difficult to distinguish whether a transfer of property rights through purchase is motivated by cultivation or asset holding. Although farmland liquidization through leasing is more general than farmland liquidization through purchase (Hayami and Godo [13]), farmland liquidization through purchase cannot be neglected. It remains as a matter to be discussed further how to build a model of farmers' decision making between the choice of purchase and lease.

5) The case where farmers both borrow and lend farmland is not considered.

6) It is assumed that farmers fully utilize labor endowment $\left(l_{\mathrm{a}}+l_{0}=\bar{L}\right)$. If a farmer leases out all endowed farmland $\left(R^{\mathrm{O}}=\bar{A}\right)$, equation (4) holds with inequality, and the amount of farmland leasing is not the function of market rent. It is also assumed that farmers who lease out all farmland do not exist.

7) The mathematical derivation is shown in the appendix of Deininger and Jin [7].

8) A referee of the journal points out that the effect of forcing farmers out of the market and the effect of changing the market rent due to transaction costs cannot be identified. Equations (15) and (16) are derived in the appendix by the linear approximation at $t^{\text {in }}=0$ and $t^{\text {out }}=0$. However, the effect of transaction costs cannot be measured exactly by the linear approximation. For example, if the market rent is affected by transaction costs, the number of farmers participating in farmland lease would also be changed. The model and the quantitative analysis in this paper do not aim to prove that the two effects of transaction costs can be distinguished. Therefore, the problem of measuring the effect of transaction costs needs further research.

9) The effect of a change of output price $p$ and technology level $\alpha$ is also derived from the first-order conditions for the factor inputs. Please refer to the appendix of Deininger and Jin [7] and for the derivation. Note that Deininger and Jin [7] assume an increase of off-farm wage does not affect a tenant $\left(\frac{\partial D}{\partial w}=0\right)$, and discuss how an increase of the wage of off-farm labor decreases the market rent and increases the amount of leased farmland through an increase of farmland supply. However, in the modern agriculture in Japan, it is possible that potential borrowers of farmers are engaged in non-farm labor. Therefore, the effect from a change in off-farm wage cannot be not uniquely determined.

10) It should also be noted that the effects of transaction costs and other exogenous factors on farmland lease on tenants and landlords are not identified; the aim of the analysis is to discuss the effect of these factors on the market equilibrium. The identification of the effects of transaction costs is a problem to be discussed further, with the availability of micro data on tenants and landlords.

11) Most of the characteristics in the public statistics are only obtained at the prefectural and community levels. The explanatory variables measured at the prefectural level may introduce measurement errors if the variance of characteristics of farmland within prefectures is large. The variables measured as the average of local communities and the ratio of corresponding communities may also bring about measurement errors if the variance of amount of farmland within communities is large. It should be noted that the panel data analysis based on the aggregated prefectural data in this paper may suffer from measurement error bias.

12) The source of the data is explained in the data appendix. See Takahashi [27] for discussion on the source of the data. The explanatory variables are determined endogenously in the agrarian structure, and can have inverse causality with the dependent variables. For example, in the area where farmland liquidization advances, functions of local communities can be active and infrastructural improvement is preferentially done. The possibility of such endogeneity can be examined with a statistical test with instrumental variables. However, the instrumental variables from prefectural data are also difficult to obtain. Therefore, the possibility of endogeneity bias should be noted.

13) The 42 prefectures analyzed in this paper dif- 
fer in the area of paddy field. Therefore, I also estimated the fixed effect estimation, weighting prefectures by the average of the area of paddy field during the analysis period. The result does not differ from the results shown in Table 2 in terms of the sign and significance of estimation. The variables on characteristics of farmland have high correlation with each other. I conducted the estimation in Table 2 with one of the variables being deleted to consider the effect of multicolinearity; the estimated coefficients and significance were not affected.

\section{References}

[1] Ando, M. “Kosaku Hoki Mondai no Wakugumi to sono Taisaku (The Framework and Solutions for the Farmland Abandonment Problem)," in Y. Yaguchi, ed., Keizai Kozo Tenkan Ki no Kyosei Nogyo System (Coexistence Farming System under the Period of Economic Structure Transformation). Tokyo: Association of Agriculture and Forestry Statistics, Ch. 5, 2006, pp. 136-171.

[2] Arimoto, Y. and S. Nakajima "Nochi no Ryudoka to Shuseki wo Meguru Ronten (Review of Liquidization and Concentration of Farmland in Japan)," Nogyo Keizai Kenkyu (Journal of Rural Economics), Vol. 82, No. 1, 2010, pp. 23-35.

[3] Carter, M.R. and Y. Yao. "Local versus Global Separability in Agricultural Household Models: The Factor Price Equalization Effect of Land Transfer Rights," American Journal of Agricultural Economics, Vol. 84, No. 3, 2002, pp. 702-715.

[4] Chino, J. “Inasaku ni okeru Kozo Hendo no Yoin Bunseki (Factor Analysis of Structural Changes in Rice Farming)," in M. Morishima, ed., Nogyo Kozo no Keiryo Bunseki (Econometric Analysis of Agricultural Structure). Tokyo: Fumin Association, Part2, Ch. 1, pp. 122-134.

[5] Ciaian, P. and J. F. M. Swinnen. "Land Market Imperfections and Agricultural Policy Impacts in the New EU Member States: A Partial Equilibrium Analysis," American Journal of Agricultural Economics, Vol. 88, No. 4, 2006, pp. 799-815.

[6] Coase, R. H. The Firm, the Market, and the Law. Chicago: University of Chicago Press, 1988.

[7] Deininger, K. and S. Jin. "The Potential of Land Rental Markets in the Process of Economic Development: Evidence from China," Journal of Development Economics, Vol. 78, No. 1, 2005, pp. 241-270.

[8] Deininger, K., S. Jin. and H. K. Nagarajan "Efficiency and Equity Impacts of Rural Land Rental Restrictions: Evidence from India," European Economic Review, Vol. 52, No. 5, 2008, pp. 892-918.

[9] Fujie, T. “Torihiki Hiyo ga Nochi Torihiki ni Oyobosu Eikyo ni kansuru Ichi Kosatsu (The Effects of Transaction Cost on Farmland Transaction: Farmland Market Model Focused on Search and Mismatch)," Nogyo Keizai Kenkyu (Journal of
Rural Economics), Vol. 75, No. 1, 2003, pp. 9-19.

[10] Godo, Y. Nihon no Shoku to Nou: Kiki no Honshitsu (The Essence of Food and Agriculture Crisis in Japan). Tokyo: NTT Publishing, 2006.

[11] Hayami, Y. Japanese Agriculture under Siege. Basingstoke: Macmillan, 1988.

[12] Hayami, Y. "Keizai Hatten ni okeru Kyodotai to Shijo no Yakuwari (The Role of Communities and Markets in Economic Development)," in Y. Sawada and T. Sonobe, eds., Shijo to Keizai Hatten (Markets and Economic Development). Tokyo: Toyo Keizai, 2006, pp. 15-41.

[13] Hayami, Y. and Y. Godo Nogyo Keizai Ron: Shin Ban (Agricultural Economics: the New Edition). Tokyo: Iwanami Shoten Publishers, 2002.

[14] Ito, J. "Inasaku no Kozo Henka to sono Chiikisei (Structural Change of the Rice Farming and the Regionality)," Nogyo Sogo Kenkyu (The Quarterly Journal of Agricultural Economy), Vol. 50, No. 4, 1996, pp. 1-45.

[15] Kajii, I. Sho Kigyo No no Sonritsu Joken (Conditions of Small Enterprising Farm). Tokyo: University of Tokyo Press, 1973.

[16] Kunimitsu, Y. Noson Kokyo Jigyo no Keizai Hyoka (Economic Evaluation on Public Project in Rural Areas). Tokyo: Association of Agriculture and Forestry Statistics, 2008.

[17] Kusakari, H. “Inasaku Noka no Kibo Kaiso kara Mita Gentan Seisaku no Keizaisei (A Quantitative Analysis of the Effects of an Acreage Allotment Program between Different Farm Size Classes in Japanese Rice Production)," Nogyo Keizai Kenkyu (Journal of Rural Economics), Vol. 61, No. 1, 1989, pp. $10-18$.

[18] Kusakari, H. "Nihon no Komesaku to Kome Seisaku no Tenkai (Rice Production in Japan and Development of the Rice Policy)," in M. Okuno and M. Honma eds., Nogyo Mondai no Keizai Bunseki (Economic Analysis of Agricultural Problems). Tokyo: Nikkei, Ch. 5, 1998, pp. 115-141.

[19] Kusakari, H. "Shinshuku teki Shuho to Shinshuku teki Shiko (The Flexible Methods and the Flexible Thoughts)," in Y. Izumida ed., Kindai Keizaigaku teki Nogyo Noson Bunseki no 50 Nen (Theoretical Economics and Agriculture: Fifty Years of Analysis). Tokyo: Association of Agriculture and Forestry Statistics, 2005, pp. 159-169.

[20] Kusakari, H. and S. Nakagawa "Fukanzen Kyoso Shijo ni okeru Beisaku Noka no Shakuchi Kodo (Optimal Behavior of Rice Farmers in the Imperfectly Competitive Land Lease Market in Japan: With a Focus on Transaction Costs and Uncertain Returns on Land Lease Investment)" $\mathrm{No}$ gyo Keizai Kenkyu (Journal of Rural Economics), Vol. 83, No. 1, 2011, pp. 28-42.

[21] Morita, K. Nochi System no Kozo to Tenkai (The Structure of Agricultural Land System and Its Development). Tokyo: Yokendo, 1998. 
[22] Nakajima, S. “Tenancy Contract Choice and Land Improvement Investment for Upland Farming," Japanese Journal of Rural Economics, Vol. 12, 2010, pp. 33-51.

[23] North, D. C. Institutions, Institutional Change and Economic Performance. New York: Cambridge University Press, 1991.

[24] Shogenji, S. ed., 21 Seiki Nihon Nogyo no Kiso Kozo (Basic Structure of Japanese Agriculture at the Turning of the Centuries). Tokyo: Association of Agriculture and Forestry Statistics, 2002.

[25] Shogenji, S. Nogyo Saiken (Reconstructing Ag- riculture). Tokyo: Iwanami Shoten Publishers, 2008.

[26] Skoufias, E. "Household Resources, Transaction Costs, and Adjustment through Land Tenancy," Land Economics, Vol. 71, No. 1, 1995, pp. 42-56.

[27] Takahashi, T. "Nochi Ryudoka to Torihiki Hiyo (Farmland Liquidization and Transaction Costs)," Nogyo Keizai Kenkyu (Journal of Rural Economics), Vol. 82, No. 3, 2010, pp. 172-185.

(Received September 27, 2011; accepted March 1, 2012) 